\title{
Research on the Innovativeness and Characteristic of Digital Media under the Environment of Internet and Big Data
}

\author{
Xing Yalei ${ }^{1}$ \\ ${ }^{1}$ China Three Gorges University, 443003 China
}

\begin{abstract}
In this paper, we conduct survey and research on the innovativeness and characteristic of digital media under the environment of Internet and big data. Under the background of the era of rapid change, the current education system is more severe impact and challenge. Creative industry is the product of cultural industry development to a new stage, is the most creative cultural industry and the origin of the core part of the new economic era of creativity industry is the condition of globalization. The research indicates that the combination of the big data with digital media is necessary and needed. In the future, we will test more related combination and creativeness.
\end{abstract}

Keywords: Digital Media; Big Data; Internet Media; Innovativeness and Characteristic.

\section{Introduction}

In the era of knowledge economy, the culture has become an important resource, economic development and the cultural industry has become one of the important pillar industries to create the considerable economic benefits, become the engine of economic development. Cultural industry is acknowledged as the sunrise industry of the 21 st century, with its unique charm and amazing growth attracted the attention of the world, more and more countries began to cultural industry as a strategic industry, whether developed countries or developing countries, have to develop the cultural industry as a new economic growth point. Creative industry is the product of cultural industry development to a new stage, is the most creative cultural industry and the origin of the core part of the new economic era of creativity industry is the condition of globalization, to people's spiritual and cultural consumption era, entertainment demand as the foundation, supported by high-tech technology, dominated by Internet in new ways, to arts and culture with the comprehensive combination of economy for its own characteristics of multinational cross-industry and more importantly inter-departmental interdisciplinary restructuring or create a new type of industrial cluster. It was based on the idea of the core, to provide public culture, art, spiritual, mental, entertainment products emerging industries. It has changed the past era of industry development of static balance which tends to be a kind of development, dynamic balance. Not only embodies the contemporary culture and economy blend mutually and embodies the culture of the culture of the new trend of economization and economy. At the same time, big data and Internet has been an important method for digital media development. Big data analysis and applications can create significant value for the world economy which will be one of the biggest market opportunities of media field in the future [1-2].

Under the background of the era of rapid change, the current education system is more severe impact and challenge. From the perspective of technology, technology change speed increased, consumption tendency increasingly significant, by the combination of technology such as virtual technology, sensor technology scheme creates endless possibilities for education. These changes not only led to digital media literacy and the digital media attention to change the height of the education, and more importantly, a kind of technology life 
cycle and influence may be related to the strategic orientation of education institutions and the future development of closely related, and even lead the deep change in the field of education. Digital media including images, text, and a variety of forms such as audio, video, and dissemination of form and content of digitization, information collection, access, processing and distribution of digital process. Its scope involves the film and television, advertising production, multimedia production, animation production development and information services, game development, architecture design, industrial design, costume design, artificial intelligence, system simulation, image analysis, virtual reality, and other fields, and covers the science and technology, art, culture, education, marketing, management and so on many levels. Digital media has become the latest after language, text, and the electronic technology of information carrier, is the main application fields are analyzed after it is not hard to see, based on the digital media development of computer and network technology to promote the development of creative industry plays an important role [3-4]. Therefore, we research the innovativeness and characteristic of digital media under the environment of Internet and big data in this paper. In the following figure one, we illustrate the basic components of digital media and related techniques.

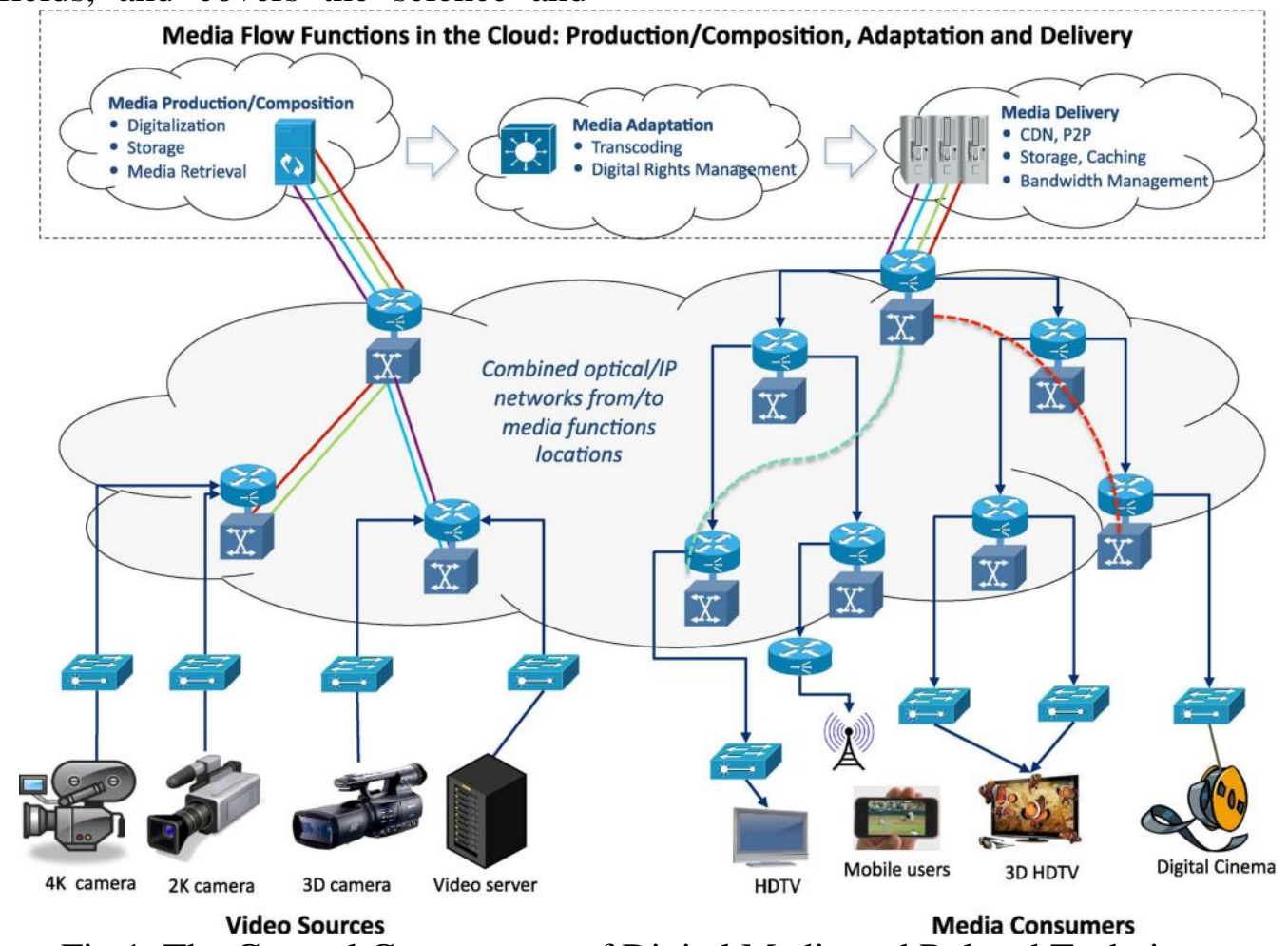

Fig 1. The General Components of Digital Media and Related Techniques

\section{The Principles of the Proposed Methodology}

The Features of Digital Media. In recent years, the rapid development of modern media, broadband digital technology, multimedia communication, and the rise of the Internet has a huge impact on traditional culture. Spread and popularization of information technology for cultural creative industry to provide the carrier, especially with the change of the Internet as the carrier of the network media makes the culture creative products spread faster. Music, photos, video, files, or dialogue can through the same kind of terminals and network to transmit and display, for mobile phone text messaging on the 
website, download ring tones, has become a fashion, in the field of entertainment, the Internet is become more and more online addiction to be bestowed favor on newly. Network media is to make the voice broadcast, television, movies, newspapers, books and other creative spread of information fusion. The large capacity of network media, immediacy, interactivity, and the important advantages of transcendence will provide people with a large number of cultural creative products provides a good route of transmission of information. It is the main and core driving force of cultural innovation, technology innovation in digital media content design and production as the center, not only to image, voice and data fusion, but also make the compatibility between different forms of media and the increased interconnectedness, breaking the previous culture and art inherent in the border, to the development of cultural creative industry has brought great vitality. Such as online games, media, advertising, animation, creative design, publishing, exhibition, etc. The industry involves image collection, processing, output and transmission process, all need to work with the help of a large number of digital technologies. With the development of cultural creative industry will demand for technology will be higher and higher demands are proposed, at the same time and the innovation of technology on the development of cultural creative industry provides a strong guarantee.
The Internet and Big Data Techniques. Big data disintegration of the traditional architecture, the information will flow into a data warehouse, connection and sharing information data pool. Big data technology makes people can take advantage of the former cannot effectively using a variety of data types, grasp the opportunity to be ignored to make enterprise organization more intelligent and efficient. Big data technology will also promote the formation of a new information security technology and product. Big data in different formats of data need to deal with the complex method. Big data including the more and more data formats which covers the semi-structured and unstructured data, the diversity of unstructured data and huge amounts of sex which determines the complexity of the technology of data and the data processing is beyond the current limits of regular data software tools are. Big data processing need to meet high timeliness. In today's rapidly changing social and economic situation, grasp the timeliness of data, is the key in an impregnable position. Of large amount of data means that the large computational overhead, biodiversity means algorithm had a better extensibility, the restricted the effectiveness of large data processing technology, real-time processing of large data for big data technology has brought a bigger challenge. In the following figure 2 , we visually illustrate the concepts of the big data technique. 


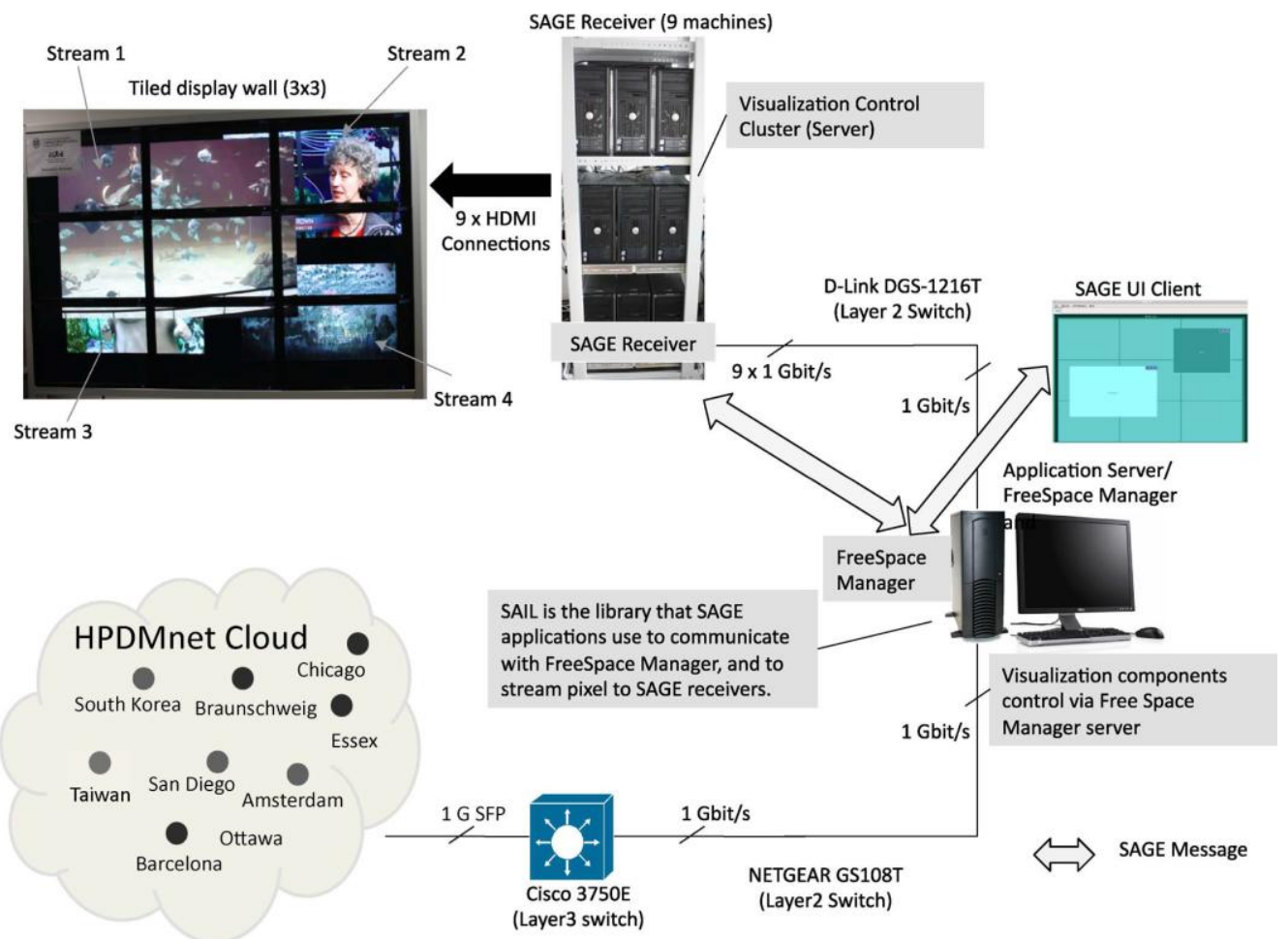

Fig 2. The General Concepts of Internet and the Big Data for Degital Media

Digital movies provided new historical opportunity for the development of the film, it has covered movies are three important links production, distribution and screening. Digital the digital special effects in the movie is Paramount, business is becoming more and more rely on special visual effects in the movie audiences, the person gives on the vision with impact and shock. In the following section, we will discuss the combination of the media with big data.

The Combination of Big Data with Digital Media. With the development of the society, the progress of science and technology, human society in the way of modern communications and marked by digital media is given priority to with culture and arts of the creative economy. Creative industry is the most creative cultural industry and a core component of the origin, it closely dependent on digital media and cultural resources, rapid development with a new attitude, become one of the important pillar industry of the current economic times. After entering the 21st century, with the rapid rise of the cultural creative industry to become the developed countries and the area industrial structure changes a prominent phenomenon. Another major concern is the condition of public service broadcasting, which in the post-communist region is still largely perceived as state broadcasting with close connections to political elites, whereas in most western European countries, particularly in northern Europe, public institutions enjoy a high degree of political and economic independence. Cultural creative industry is the global rise of the knowledge economy under the conditions of urban industry and the trend of consumption upgrade, at the same time, the development of cultural creative industry and prosperity not only directly promote the rapid development of modern service industry, but also through creative design, brand cultivation, marketing planning and so on to improve the additional value of the manufacturing products, thereby gives the impetus to the development of advanced manufacturing industry. Potential of cloud computing is huge, the cloud computing model 
are also increasingly mature, but its popularization application there are many key problems need to solve. For cultural creative industry, product differentiation is the important characteristic, and the differences of the popularization of information technology and the improvement for the product to provide better development platform. In low cost the characteristics of the digital media and digital two-way transmission to the spread of creative industry has brought unique advantages, reduce the cost, at the same time, digital technology and continuously improve the performance of also brought cultural creative industry has reduced the cost of a lot of space. In the following figure, we show the sample.

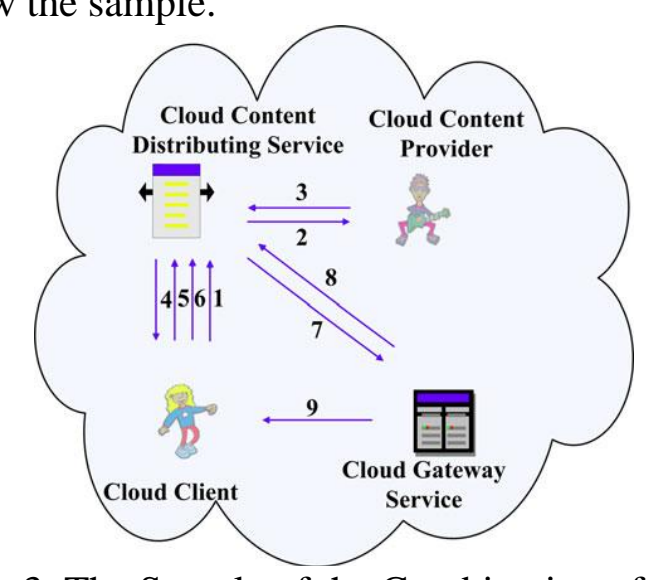

Fig 3. The Sample of the Combination of Big Data with Degital Media

\section{Conclusion}

In this paper, we conduct survey and research on the innovativeness and characteristic of digital media under the environment of Internet and big data. With the development of the society, the progress of science and technology, human society in the way of modern communications and marked by digital media is given priority to with culture and arts of the creative economy. Through adding the concepts and techniques of big data and Internet platform, we could easily analyze the efficiency of adding the novel component into the chain. In the future, more combination will be implemented.

\section{References}

[1] Shaikh, A. R., Butte, A. J., Schully, S. D., Dalton, W. S., Khoury, M. J., \& Hesse, B. W. (2014). Collaborative biomedicine in the age of big data: the case of cancer. Journal of Medical Internet Research, 16, 4, 143-147.

[2] Sand, G., Tsitouras, L., Dimitrakopoulos, G., \& Chatzigiannakis, V. (2015). Globalifusion, the first worldwide, holistic, information \& communication technologies (ict) and big data aggregation approach to social media marketing. Working Papers.

[3] Shelton T, Poorthuis A, Graham M, et al. Mapping the data shadows of Hurricane Sandy: Uncovering the sociospatial dimensions of 'big data' $[\mathrm{J}]$. Social Science Electronic Publishing.

[4] Globant A, Schneider A, Director T, et al. Big Data[J]. Datenschutz und Datensicherheit - DuD, 2013, 37(5):273. 